\title{
Dexamethasone shifts bone marrow stromal cells from osteoblasts to adipocytes by C/EBPalpha promoter methylation
}

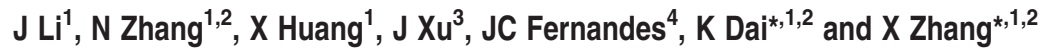

Dexamethasone (Dex)-induced osteoporosis has been described as the most severe side effect in long-term glucocorticoid therapy. The decreased bone mass and the increased marrow fat suggest that Dex possibly shifts the differentiation of bone marrow stromal cells (BMSCs) to favor adipocyte over osteoblast, but the underlying mechanisms are still unknown. In this paper, we established a Dex-induced osteoporotic mouse model, and found that BMSCs from Dex-treated mice are more likely to differentiate into adipocyte than those from control mice, even under the induction of bone morphogenetic protein-2 (BMP2). We also discovered both in vitro and in vivo that the expression level of adipocyte regulator CCAAT/enhancer-binding protein alpha (C/EBPalpha) is significantly upregulated in Dex-induced osteoporotic BMSCs during osteoblastogenesis by a mechanism that involves inhibited DNA hypermethylation of its promoter. Knockdown of C/EBPalpha in Dex-induced osteoporotic cells rescues their differentiation potential, suggesting that Dex shifts BMSC differentiation by inhibiting C/EBPalpha promoter methylation and upregulating its expression level. We further found that the Wnt/beta-catenin pathway is involved in Dexinduced osteoporosis and C/EBPalpha promoter methylation, and its activation by $\mathrm{LiCl}$ rescues the effect of Dex on C/EBPalpha promoter methylation and osteoblast/adipocyte balance. This study revealed the C/EBPalpha promoter methylation mechanism and evaluated the function of Wnt/beta-catenin pathway in Dex-induced osteoporosis, providing a useful therapeutic target for this type of osteoporosis.

Cell Death and Disease (2013) 4, e832; doi:10.1038/cddis.2013.348; published online 3 October 2013

Subject Category: Experimental Medicine

Dexamethasone (Dex), a potent synthetic member of the glucocorticoid (GC) class of steroid drugs, is widely used as an immune suppressor. However, chronic Dex therapy is associated with side effects including bone loss, low bone mineral density (BMD), and increased fracture risk, which has been described as the most severe complication of long-term $\mathrm{GC}$ therapy. At the time of writing, no effective method exists to treat these side effects of Dex. Clinical investigation has shown that Dex-induced osteoporosis is accompanied by increased bone marrow adiposity. ${ }^{1-3}$ Osteoblasts and adipocytes both arise from the same progenitor cells and bone marrow stromal cells (BMSCs). Reports show that a reciprocal relationship exists between osteoblast and adipocyte differentiation, and BMSCs differentiating into one lineage gradually lose the ability to differentiate to the other. ${ }^{4,5}$ Therefore, the decreased bone formation and increased marrow adiposity in
Dex-induced osteoporotic patients increase the possibility that the differentiation balance between osteoblast and adipocyte is shifted by Dex.

BMSC differentiation into certain lineages is strictly controlled by several transcription factors. Runt-related transcription factor 2 and Osterix (Osx) are master regulators of osteoblastogenesis, ${ }^{6,7}$ whereas adipocyte differentiation is triggered by CCAAT/enhancer-binding protein alpha (C/EBPalpha) and peroxisome proliferator-activated receptor gamma (PPARgamma). ${ }^{8}$ Several reports have shown that C/EBPalpha and PPARgamma could prevent osteoblast differentiation, ${ }^{9}$ so their expressions are inhibited during osteoblastogenesis by unknown mechanisms ${ }^{10}$ ).

Our previous research indicates that C/EBPalpha gene expression is downregulated at the late stage of bone morphogenetic protein-2 (BMP2)-induced osteoblast

\footnotetext{
${ }^{1}$ The Key Laboratory of Stem Cell Biology, Institute of Health Sciences, Shanghai Institutes for Biological Sciences (SIBS), Chinese Academy of Sciences (CAS), Shanghai Jiao Tong University School of Medicine (SJTUSM), China; ${ }^{2}$ Shanghai Key Laboratory of Orthopaedic Implant, Department of Orthopaedic Surgery, Shanghai Ninth People's Hospital, Shanghai Jiao Tong University School of Medicine (SJTUSM), China; ${ }^{3}$ School of Pathology and Laboratory Medicine, The University of Western Australia (M504), 35 Stirling Highway, Crawley, Western Australia 6009, Australia and ${ }^{4}$ Orthopaedics Research Laboratory, Research Center, Sacré-Coeur Hospital, University of Montreal, 5400 Gouin Boulevard, West Montreal, Quebec, Canada H4J 1C5

${ }^{*}$ Corresponding authors: K Dai or X Zhang, The Key Laboratory of Stem Cell Biology, Institute of Health Science, Room 101, No. 225, South Chongqing Road, Shanghai 200025, China. Tel/Fax: +86 2163139920 or +86 216385 5434; E-mails: krdai@ sibs.ac.cn or xlzhang@ sibs.ac.cn

Keywords: osteoporosis; BMSC differentiation; Wnt/beta-catenin; C/EBPalpha; DNA methylation

Abbreviations: Dex, dexamethasone; C/EBP, CCAAT/enhancer binding protein; BMSCs, bone marrow stromal cells; BMP, bone morphogenetic protein; LiCl, lithium chloride; Wnt, wingless; GC, glucocorticoid; BMD, bone mineral density; Osx, osterix; PPAR, peroxisome proliferator-activated receptor; Col, collagen; Ocn, osteocalcin; aP2, fatty acid-binding protein-4; Glut4, glucose transporter type 4; FBS, fetal bovine serum; IFMD, insulin, FBS, methylisobutylxanthine and Dex; qRT-PCR, quantitative reverse transcription PCR; Dnmt, DNA methyltransferase; ChIP, chromatin immunoprecipitation; Co-IP, co-immunoprecipitation; GR, glucocorticoid receptor; DKK, Dickkopf; GSK, glycogen synthase kinase; SFRP, secreted frizzled-related protein; DAPI, 4', 6-diamidino-2-phenylindole; TUNEL, terminal dexynucleotidyl transferasemediated dUTP nick end labeling; shRNA, short hairpin RNA; PBS, phosphate-buffered saline; SDS, sodium dodecyl sulfate; EDTA, ethylenediaminetetraacetic acid Received 29.4.13; revised 01.8.13; accepted 12.8.13; Edited by M Agostini
} 
differentiation of mouse mesenchymal cell line C3H10T1/2. Its overexpression can prevent osteoblastogenesis. One of the mechanisms inhibiting C/EBPalpha expression is DNA hypermethylation. We found that the $\mathrm{CpG}$ island of the distal promoter region $(-1286 \mathrm{bp} /-1065 \mathrm{bp})$ of C/EBPalpha is hypermethylated at late-stage osteoblast differentiation, and the balance between osteoblastogenesis and adipogenesis is broken when methylation is interrupted ${ }^{11}$ In this study, we postulated that the differentiation potential of BMSCs in Dex-induced osteoporosis changes to favor adipocytes over osteoblasts, and C/EBPalpha has a function in this process. To test this hypothesis, we established an osteoporotic mouse model by Dex administration. We observed that excess Dex resulted in bone loss and increased marrow fat in our model. We found that compared with control mice, BMSCs from Dex-induced osteoporotic mice exhibited reduced osteoblast differentiation and increased adipocyte formation. C/EBPalpha was highly expressed both in vivo and in vitro, and its promoter maintained low methylation in Dex-induced osteoporotic BMSCs even after 21 days of osteogenic induction. These findings suggest that Dex shifted the differentiation balance between osteoblast and adipocyte by inhibiting DNA hypermethylation of the C/EBPalpha promoter during osteoblastogenesis. We further determined the function of Wnt/beta-catenin pathway in Dex-induced osteoporosis and C/EBPalpha promoter methylation mechanism, and evaluated the effect of Wnt agonist $\mathrm{LiCl}$ on Dex-induced BMSCs during osteoblastogenesis inhibition.

\section{Results}

Mice with excess Dex administration exhibited reduced bone density and increased marrow fat. To investigate the molecular mechanisms of Dex-induced osteoporosis, we first established a mouse osteoporotic model by excess Dex administration ( $50 \mathrm{mg} / \mathrm{kg}$ daily) for 5 weeks. MicroCT analysis showed reduced trabecular bone in the distal femur (Figure 1a), lower BMD, bone volume, trabecular number and thickness, and higher trabecular space in Dex-induced osteoporotic mice (Figure 1b), indicating that bone mass was decreased by long-term Dex administration. Histologic analysis showed reduced trabecular bone and significantly increased adipocytes in the trabecular bone marrow space (Figure 1c). These data are consistent with clinical observations $^{1,2}$ and indicate that Dex stimulates BMSCs to differentiate into adipocytes instead of osteoblasts.

BMSCs from Dex-induced osteoporotic mice exhibited reduced osteoblastogenesis and higher adipocyte differentiation potential. To test the possibility that the differentiation potential of BMSCs was changed by Dex, we cultured primary BMSCs from both Dex-induced osteoporotic mice and saline-treated control mice in vitro. BMSCs from Dex-treated osteoporotic mice exhibited deceased proliferation (Figure 2a), yet cell apoptosis were not significantly different from control BMSCs (Figure $2 b$ ). We than performed osteoblastic differentiation assay and quantified changes in key osteoblast marker genes Osx, type I collagen (Col1a1), and osteocalcin (Ocn) at different time points to assess the degree of BMSC osteoblastogenesis. The results show that the expression of Osx, Col1a1, and Ocn were significantly induced by BMP2 from day 7 in normal BMSCs. However, these osteoblast marker genes remained at low expression levels in Dex-induced osteoporotic cells throughout induction (Figure 2c). By contrast, adipocyte marker gene fatty acidbinding protein-4 (aP2) and glucose transporter type 4 (Glut4) were highly upregulated in Dex-induced osteoporotic BMSCs, even under BMP2 treatment (Figure 2c).

As we observed high expression levels of adipocyte markers in Dex-induced osteoporotic BMSCs, we estimated that the adipogenic conversion potential remained in these cells even after 21 days of osteogenic induction by BMP2. To test this hypothesis, we cultured BMSCs in a medium containing $100 \mathrm{ng} / \mathrm{ml}$ BMP2 for 21 days, which was then switched to adipogenic cocktail IFMD for an additional 8 days. Quantitative reverse transcription PCR (qRT-PCR) showed that adipocyte genes aP2 and Glut4 could hardly be induced by IFMD in normal BMSCs after 21 days of BMP2 treatment, whereas in Dex-induced osteoporotic BMSCs, these genes were highly induced, with or without BMP2 treatment (Figure 2d). Oil red O-stained lipid drops of transdifferentiated adipocytes also indicated the higher adipogenic conversion potential of Dex-induced osteoporotic cells than those from normal mice (Figure 2e).

To address the possibility that the changed differentiation potential of BMSCs by Dex also exists in vitro, we performed parallel studies with $\mathrm{C} 3 \mathrm{H} 10 \mathrm{~T} 1 / 2$ cells. C3H10T1/2 is a mouse mesenchymal cell line that can differentiate equally into both osteoblast and adipocyte. Our laboratory successfully established an osteoblast differentiation model of C3H10T1/2 induced by $\mathrm{BMP}^{11}$. In this study, С $3 \mathrm{H} 10 \mathrm{~T} 1 / 2$ cells were incubated with BMP2 $(100 \mathrm{ng} / \mathrm{ml})$ plus Dex $\left(10^{-6} \mathrm{M}\right)$ at specific times, and the expression levels of both osteoblast and adipocyte genes were tested. The expression of osteoblast genes Osx, Col1a1, and Ocn were significantly inhibited by Dex from day 7 (Figure 2f), whereas adipocyte genes aP2 and Glut4 were highly induced (Figure 2f). To detect the dose effect of Dex on adipogenic conversion during osteoblastogenesis, cells were pre-treated with different doses of Dex and BMP2 for 21 days before the medium was replaced by IFMD. Adipocyte gene expression changes indicated that the effect of Dex on inducing adipogenic conversion of $\mathrm{C} 3 \mathrm{H} 10 \mathrm{~T} 1 / 2$ cells was dose-dependent. The low concentration of Dex $\left(10^{-9}-10^{-8} \mathrm{M}\right)$ lost such ability (Figure $2 \mathrm{~g}$ ). Oil red $\mathrm{O}$ shows the lipid drops in adipocytes converted from cells treated with $10^{-6} \mathrm{M}$ Dex and BMP2 (Figure 2h). These results indicate that Dex inhibited osteoblast differentiation induced by BMP2 and shifted the balance of BMSC differentiation to favor adipocytes by improving adipocyte gene expression.

Dex promoted C/EBPalpha expression by inhibiting DNA methylation of its promoter at the late osteoblast differentiation stage. In our previous research, we found that the expression level of adipocyte master regulator $\mathrm{C} /$ EBPalpha in osteoblast differentiation was consistent with adipogenic conversion ability ${ }^{11}$. Next, we detected its mRNA and protein levels at different times during osteoblast differentiation of both Dex-induced osteoporotic BMSCs and Dex-treated C3H10T1/2 cells. We found that C/EBPalpha 

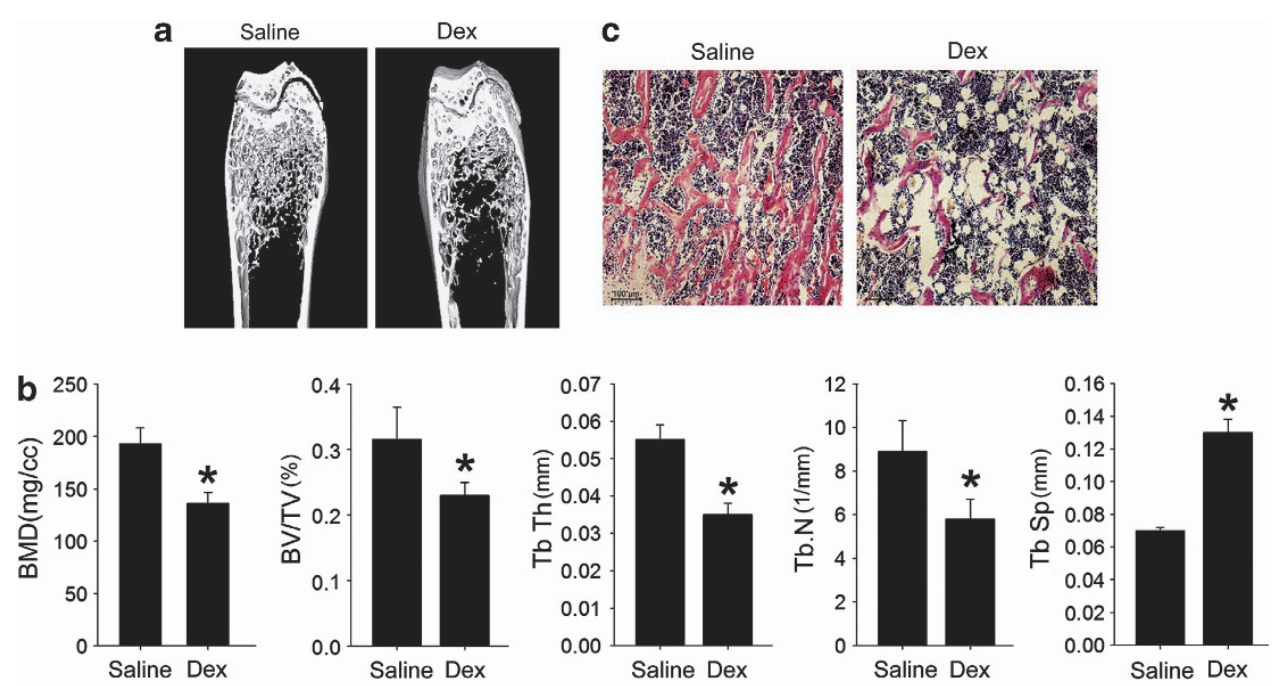

Figure 1 Dex-induced osteoporosis and increased marrow fat. (a) Reduced trabecular bone in microCT images of the distal femur of Dex-administered mice compared with control mice. $\mathrm{N}=3$. (b) MicroCT analysis indicated reduced femur BMD, trabecular bone volume as a percentage of total volume (BV/TV), trabecular bone numbers (Tb.N), trabecular bone thickness (Tb.Th), and increased trabecular spacing (Tb.Sp) in Dex-treated mice compared with control mice. Data are presented as mean \pm S.D. of three independent experiments. ${ }^{*} P<0.05, N=3$. (c) Reduced trabecular bone and increased adipocyte number in H\&E sections from the distal femur of Dex-treated mice. $N=4$

was highly expressed in Dex-induced osteoporotic BMSCs, and the high levels of both mRNA and protein were maintained for 21 days during BMP2 induction. By contrast, the mRNA and protein levels of C/EBPalpha in control cells were barely detectable at late stages (day 21) of differentiation (Figure 3a above). In C3H10T1/2 cells, Dex improved C/EBPalpha expression from day 7 and inhibited its downregulation at day 21 (Figure 3a below). To confirm the aforementioned results in vivo, we conducted immunohistochemical assays with the proximal tibia of both Dex-induced osteoporotic and control mice and found that the C/EBPalpha protein level was significantly higher in Dex-administered bone marrow areas (Figure 3b).

Our previous work also found that the main mechanism that downregulates C/EBPalpha expression at late-stage osteoblast differentiation is DNA hypermethylation of its distal promoter (-1289 bp/ - $1065 \mathrm{bp}$ ). C/EBPalpha was still highly expressed even after 21 days of BMP2 induction both in Dexinduced osteoporotic BMSCs and Dex-treated C3H10T1/2 cells. Thus, we postulated that DNA methylation is interrupted by Dex. To test whether the methylation status was changed, C/EBPalpha promoter DNA from both Dex-induced osteoporotic and control BMSCs treated with BMP2 for 21 days were subjected to bisulfite sequencing. The results show that compared with the hypermethylation status in normal BMSCs, $\mathrm{C} / \mathrm{EBPalpha}$ promoter remained unmethylated in Dex-induced osteoporotic cells (Figure 3c). In the C3H10T1/2 cells, $\mathrm{C} / \mathrm{EBP}$ alpha promoter methylation was also inhibited by $10^{-6}$ M Dex (Figure 3c). To investigate the molecular mechanisms by which Dex regulates C/EBPalpha promoter methylation, we first detected the protein level of de novo DNA methyltransferases 3a and $3 b$ (Dnmt 3a/3b). Total proteins extracted from C3H10T1/2 cells treated with or without Dex for 21 days were subjected to western blot analysis. The results show that Dex did not significantly change the protein level of Dnmt 3a/3b (Figure 3d). We then performed chromatin immunoprecipitation (ChIP) assay with $\mathrm{C} 3 \mathrm{H} 10 \mathrm{~T} 1 / 2$ cells. Compared with BMP2 treatment only, we observed that the binding of Dnmt 3a/3b to C/EBPalpha promoter was blocked (Figure $3 e$ ). These results suggest that Dex upregulated C/EBPalpha expression level by preventing Dnmt $3 a / 3 b$ from binding to C/EBPalpha promoter, thereby inhibiting its hypermethylation during osteoblast differentiation.

C/EBPalpha knockdown rescued the effect of Dex on differentiation balance between osteoblast and adipocyte. To test whether C/EBPalpha has a pivotal function in shifting osteoblast and adipocyte differentiation balance during Dex treatment, we used shRNA to knockdown C/EBPalpha in Dex-induced osteoporotic BMSCs. The efficiency of our shRNA was confirmed by western blot (Figure 4a). Stable transfected BMSCs were used to repeat osteoblast differentiation and transdifferentiation assay. The results show that osteoblast genes Osx, Col1a1, and Ocn were upregulated, whereas adipocyte genes aP2 and Glut4 were more significantly inhibited by shC/EBPalpha compared with the shControl (Figure 4b). In the transdifferentiation assay, shC/EBPalpha also rescued the adipocyte conversion ability of Dex-induced osteoporotic BMSCs (Figure 4c).

Wnt/beta-catenin pathway is involved in Dex-induced osteoporosis and C/EBPalpha methylation. The effect of Dex is through binding and activating glucocorticoid receptor (GR). It is possible that Dex-GR complex blocked the binding of Dnmt $3 a / b$ to C/EBPalpha promoter through interacting with Dnmt $3 a / 3 b$ or binding the C/EBPalpha promoter on a Dnmt $3 a / 3 b$-binding site. To test this possibility, we performed ChIP and co-immunoprecipitation (Co-IP) assay. After 21 days of treatment with Dex, we did not find the interactions of GR with Dnmt 3a/b or C/EBPalpha promoter in C3H10T1/2 cells (Figure $5 \mathrm{a}$ and b), indicating Dex-GR complex inhibits C/EBPalpha promoter methylation indirectly through regulating down-strain target genes or signaling pathways. 
Several reports have indicated that Dex prevents osteoblastogenesis partly by inhibiting the Wnt/beta-catenin pathway, ${ }^{12-14}$ one of the most important signaling pathways in
BMP2-induced osteoblastogenesis. ${ }^{15}$ To investigate whether the $\mathrm{Wnt} /$ beta-catenin pathway is involved in Dex-induced osteoporosis and C/EBPalpha methylation, we tested this

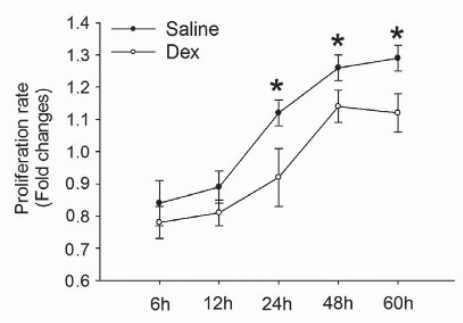

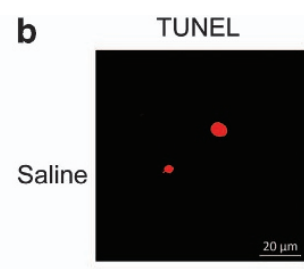

BMSCs

c
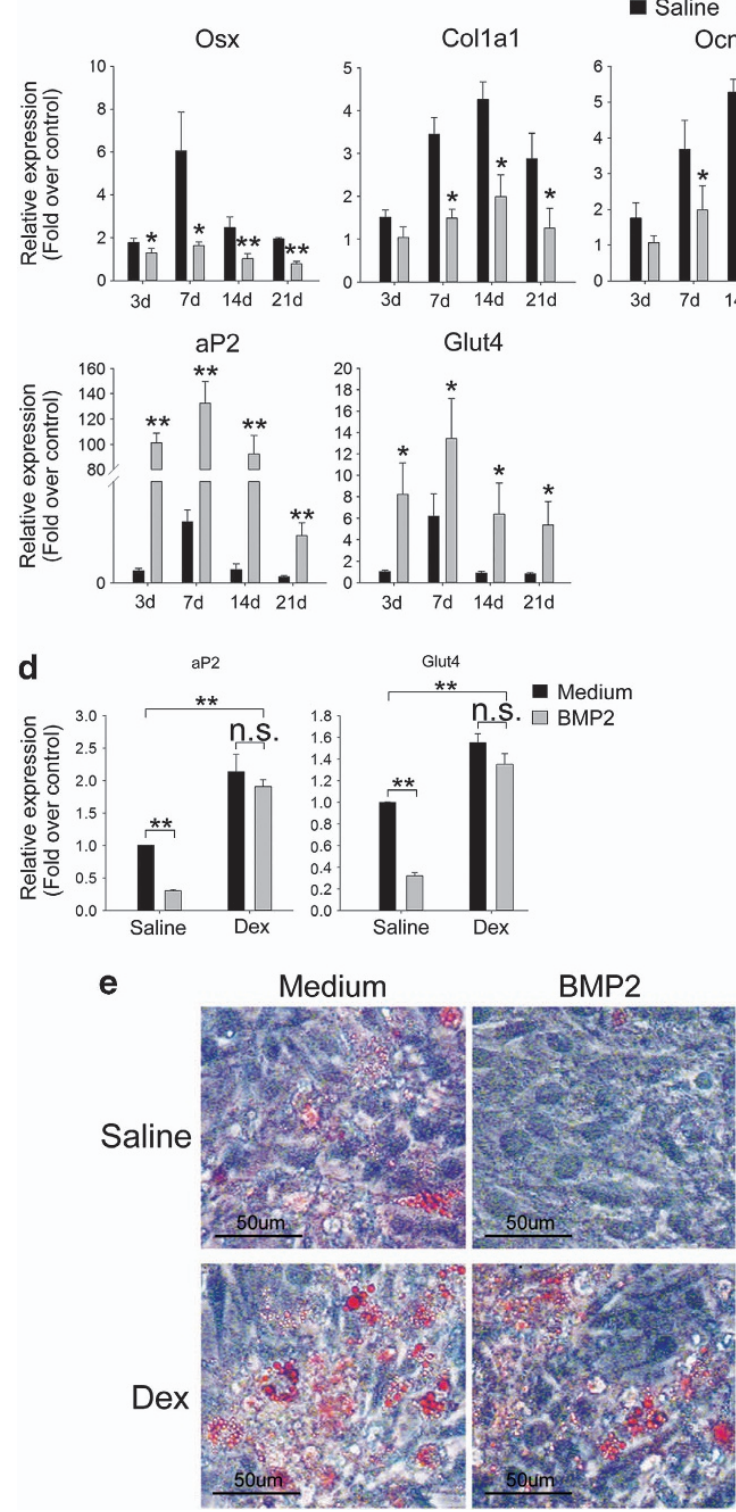

h

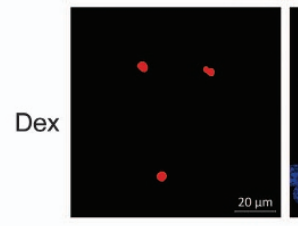

DAPI

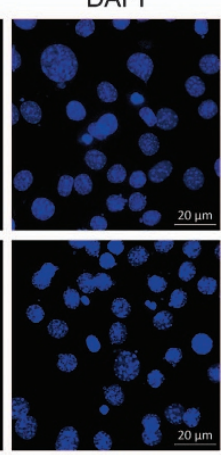

f - Saline $\square$ Dex Ocn

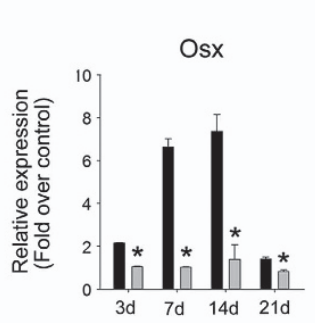

C3H10T1/2
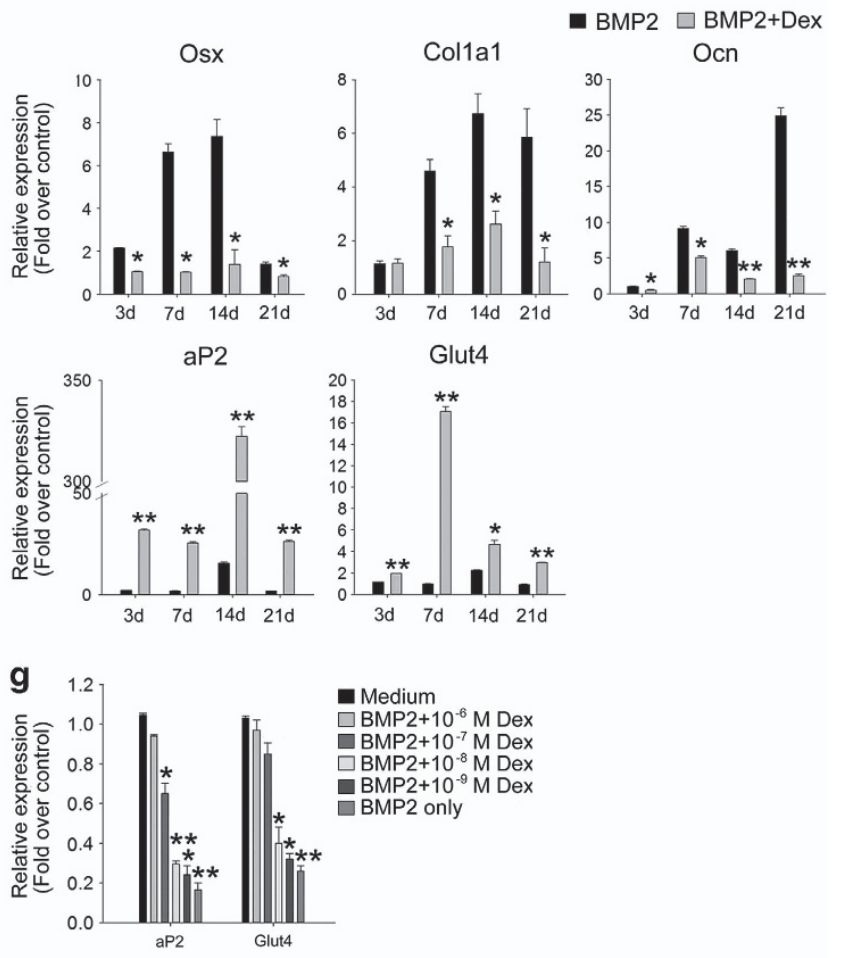
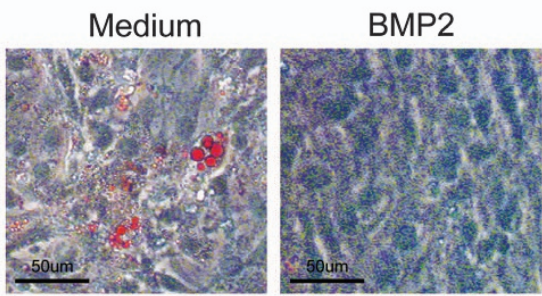

BMP2+Dex

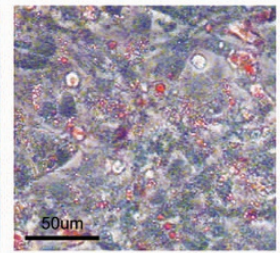


pathway in our osteoporotic model both in vivo and in vitro. In vivo, immunohistochemistry with femurs from Dex-induced osteoporotic mice indicated lower protein level of active beta-catenin compared with those of the control mice (Figure 5c). In vitro, the protein level of active beta-catenin was also significantly lower in $\mathrm{C} 3 \mathrm{H} 10 \mathrm{~T} 1 / 2$ cells cultured with $10^{-6} \mathrm{M}$ Dex and BMP2 than those cultured in BMP2 only (Figure $5 d$ ). The qRT-PCR results show that the inducibility of BMP2 on Wnt target genes Axin2 and CyclinD1 ${ }^{16,17}$ failed, whereas the expression of the canonical Wnt pathway inhibitor DKK1 was higher (Figure 5e) in Dex-treated cells compared with BMP2 treatment only. These results indicate that the Wnt/beta-catenin pathway was blocked by Dex both in vitro and in vivo.

Next, we evaluated the function of Wnt/beta-catenin signaling in established DNA methylation status of C/EBPalpha promoter and in differentiation balance between osteoblasts and adipocytes by BMP2. We blocked this pathway with IWR-1 $\left(10^{-6} \mathrm{M}\right)^{18}$ during the BMP2 induction of $\mathrm{C} 3 \mathrm{H} 10 \mathrm{~T} 1 / 2$ cells. The protein level of beta-catenin and the mRNA level of Wnt target genes Axin2 and CyclinD1 (Figure 5f) all attested to the inhibitory effect of IWR-1. The differentiation balance between osteoblasts and adipocytes and the DNA methylation status of C/EBPalpha promoter were detected after 21 days of
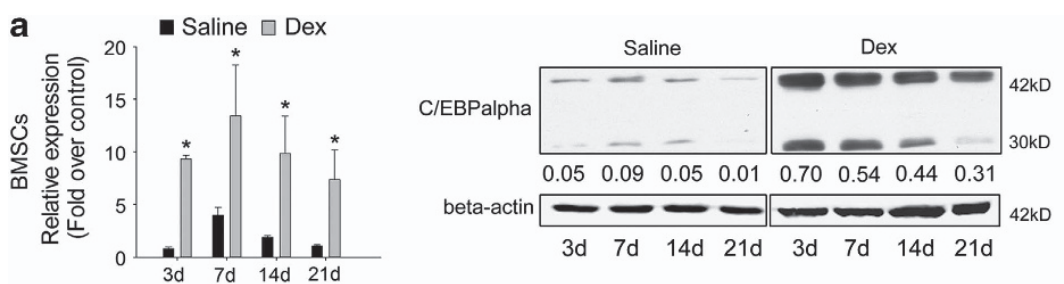

b
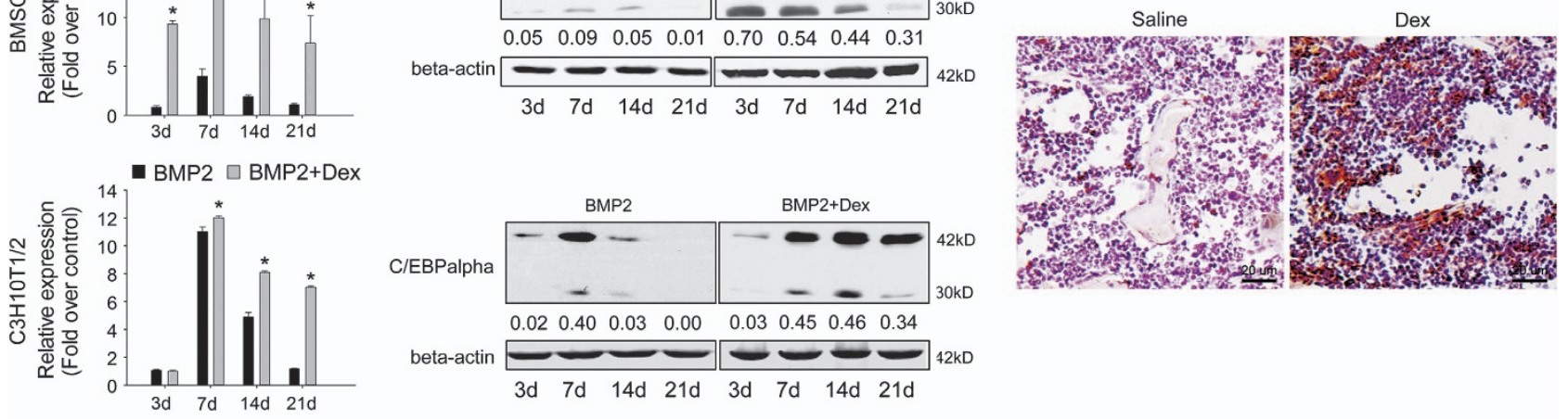

C

BMSCs

$\mathrm{C} 3 \mathrm{H} 10 \mathrm{~T} 1 / 2$
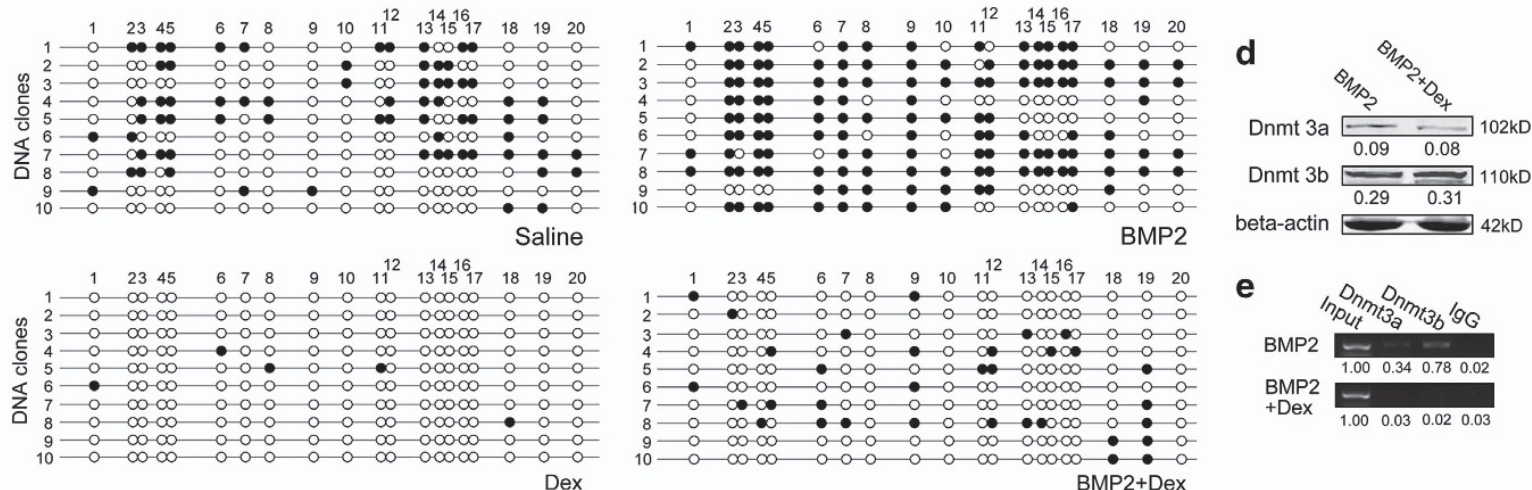

Figure 3 Dex upregulates C/EBPalpha during osteoblastogenesis by inhibiting DNA methylation of the C/EBPalpha promoter. (a) mRNA and protein levels of C/EBPalpha in indicated BMSCs cultured with $100 \mathrm{ng} / \mathrm{ml} \mathrm{BMP2} \mathrm{(above),} \mathrm{as} \mathrm{well} \mathrm{as} \mathrm{in} \mathrm{C3H10T1/2} \mathrm{cells} \mathrm{treated} \mathrm{as} \mathrm{indicated.} \mathrm{Relative} \mathrm{mRNA} \mathrm{expressions} \mathrm{were} \mathrm{normalized} \mathrm{to} \mathrm{beta-actin.}$ Data are presented as mean \pm S.D. of three independent experiments. ${ }^{*} P<0.05, N=3$. (b) The in vivo C/EBPalpha expression levels in the distal femur area of Dex- or saline-treated mice were shown by immunohistochemistry. $N=4$. (c) C/EBPalpha promoter methylation status in indicated BMSCs treated with BMP2, as well as in C3H10T1/2 cells treated as indicated for 21 days (open circle: unmethylated CpG; full circle: methylated CpG; 10 clones in each group were tested). $N=3$. (d) Protein levels of Dnmt $3 a / 3 b$ in C3H10T $1 / 2$ cells treated as indicated for 21 days (above). $N=3$. (e) ChIP assay shows the binding of Dnmt $3 \mathrm{a} / 3 \mathrm{~b}$ to the C/EBPalpha promoter in C3H10T1/2 cells after 21 days of BMP2 treatment. $N=3$. Densitometric analysis was shown as fold changes relative to beta-actin (Western blot) or input (ChIP)

Figure 2 Suppressed osteoblastogenesis and increased adipogenesis of Dex-induced osteoporotic BMSCs. (a) Proliferation of BMSCs from both Dex-and Saline-treated mice measured by MTT assay. (b) Apoptosis of BMSCs cultured in growth medium were detected by TUNEL staining. (c) Relative expressions of osteoblast and adipocyte markers in BMSCs from Dex- or saline-treated mice under the induction of BMP2 to indicated times were quantified by qRT-PCR. (d) Relative expressions of adipocyte genes in BMSCs from Dex- or saline-treated mice were quantified by qRT-PCR in transdifferentiation assay. (e) Oil red O staining of the transdifferentiated adipocytes from indicated cells showed higher adipocyte conversion potential of osteoporotic BMSCs. $N=3$. Respective cells cultured in the growth medium were used as control. (f) The expressions of osteoblast and adipocyte markers in C3H10T1/2 cells treated as indicated were quantified by qRT-PCR. (g) Relative expressions of adipocyte genes in transdifferentiated $\mathrm{C} 3 \mathrm{H} 10 \mathrm{~T} 1 / 2$ cells that were treated with different doses of Dex. (h) Oil red O staining shows the transdifferentiated adipocytes from cells treated by $10^{-6} \mathrm{M}$ Dex. Cells cultured in the growth medium were used as control. $N=3$. All mRNA expression levels were normalized to beta-actin. Data are presented as mean $\pm S$.D. of three independent experiments. ${ }^{*} P<0.05,{ }^{* *} P<0.01$, n.s. $P>0.05, N=3$ 

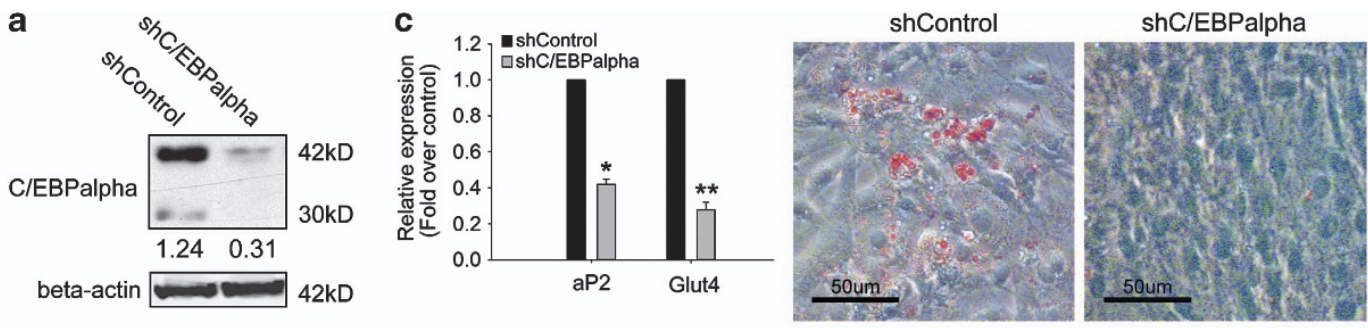

b mshControl $\square$ shC/EBPalpha
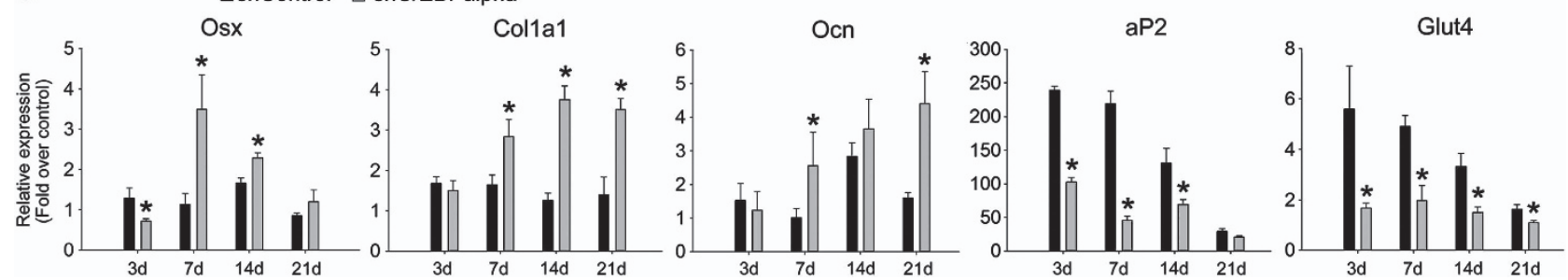

Figure 4 Knockdown of C/EBPalpha partly rescued the differentiation fate of Dex-induced osteoporotic BMSCs. (a) The knockdown efficiency of lentivirus encoding C/EBPalpha-targeting shRNA (shC/EBPalpha) was confirmed by comparison to control lentivirus (shControl). (b) Expression levels of both osteoblast genes and adipocyte genes in osteoporotic BMSCs treated by BMP2 after shC/EBPalpha or shControl infections at $10 \mathrm{MOI}$. (c) In the transdifferentiation assay, the expression levels of adipocyte genes, and the transdifferentiated adipocytes of osteoporotic BMSCs after indicated shRNA infection were shown by qRT-PCR and oil red O staining, respectively. All mRNA expression levels were normalized to beta-actin. Data are presented as mean \pm S.D. of three independent experiments. ${ }^{\star} P<0.05,{ }^{\star \star} P<0.01, N \geq 3$. Densitometric analysis was shown as fold changes relative to beta-actin

treatment. The results show that osteoblast genes Osx, Col1a1, and Ocn were all downregulated, whereas adipocyte genes C/EBPalpha, aP2, and Glut4 were all significantly upregulated (Figure $5 \mathrm{~g}$ ). Cells could transdifferentiate into adipocytes (Figure 5h) after 21 days of BMP2 induction, and the methylation process of C/EBPalpha promoter was inhibited (Figure 5i), which is similar to the cells treated with Dex. These results indicate that the Wnt/beta-catenin pathway is indispensible in BMP2-induced osteoblast differentiation, inhibition of adipogenesis, and downregulation of C/EBPalpha through DNA hypermethylation.

\footnotetext{
Activation of Wnt/beta-catenin by $\mathrm{LiCl}$ partly rescued the effect of Dex on BMSC differentiation and C/EBPalpha promoter methylation. To test whether activation of the Wnt/beta-catenin pathway can rescue the effect of Dex on BMSC differentiation, the canonical Wnt agonist $\mathrm{LiCl}$ and BMP2 were used to treat Dex-induced osteoporotic cells. $\mathrm{LiCl}$ has been reported to stimulate the Wnt pathway by improving the degradation of GSK3-beta, whereas Dex had no effect on LiCl-induced Wnt activity. ${ }^{13}$ Treatment of $20 \mathrm{mM}$ $\mathrm{LiCl}$ and BMP2 improved osteoblast gene (Osx and Ocn) expression in Dex-induced osteoporotic cells from day 14, whereas the rescue effect of $\mathrm{LiCl}$ on Col1a1 was less obvious (Figure 6a). However, LiCl treatment significantly inhibited C/EBPalpha expression and other adipocyte genes aP2 and Glut4, which were highly expressed in Dex-induced osteoporotic BMSCs (Figure 6a). LiCl also completely reversed the adipogenic conversion potential of Dex-induced osteoporotic BMSCs (Figure 6b). The hypermethylation state of C/EBPalpha promoter in Dex-induced osteoporotic BMSCs was recovered after 21 days of treatment with BMP2 and $\mathrm{LiCl}$ (Figure 6c). In parallel tests with C3H10T1/2 cells cultured in BMP2, $10^{-6} \mathrm{M}$ Dex and $20 \mathrm{mM}$ LiCl displayed largely similar
}

effects as the primary cells. LiCl partly reversed the effect of Dex on osteoblast and adipocyte gene expression (Figure 6d), adipocyte conversion potential (Figure 6e), and $\mathrm{C} /$ EBPalpha promoter methylation (Figure 6f). $\mathrm{LiCl}$ did not change the protein level of Dnmt 3a/3b (Figure $6 \mathrm{~g}$ ), but rescued their binding property on $\mathrm{C} / \mathrm{EBPalpha}$ promoter (Figure 6h), thereby recovering its methylation status. These results suggest that the effect of Dex on differentiation balance between osteoblasts and adipocytes of BMSCs and $\mathrm{C} / \mathrm{EBPalpha}$ promoter methylation is partly through the inhibition of the Wnt/beta-catenin pathway.

\section{Discussion}

According to recent studies, the mechanisms of Dex-induced osteoporosis can be summarized as follows: first, Dex inhibits osteoblast proliferation and induces its apoptosis; ${ }^{12,13}$ second, Dex increases osteoclast number, thus improving bone resorption. ${ }^{14}$ However, the exact reason for increased marrow fat in osteoporotic patients is still unknown. BMSCs from osteoporotic patients in vitro culture are more likely to differentiate into adipocytes instead of osteoblasts, ${ }^{19,20}$ which increases the possibility that Dex can also shift BMSC differentiation to favor adipocytes, resulting in reduced osteoblast number and increased marrow adiposity during long-term administration. In our Dex-induced osteoporotic mouse model, we also observed increased adipocytes in the bone marrow besides bone loss. The results of the repressed osteoblast genes but highly induced adipocyte genes and the higher adipogenic conversion potential of in vitro cultured BMSCs from Dex-induced osteoporotic mice confirm the arrested differentiation of the osteoblast lineage with a subsequent shift toward adipocyte differentiation. 
a

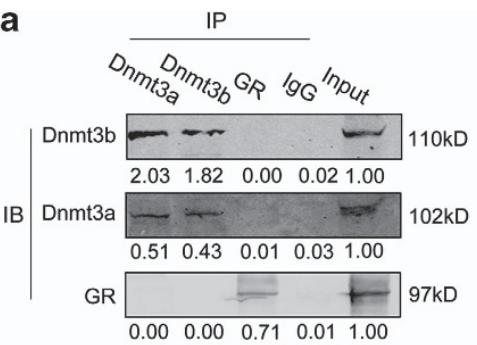

b

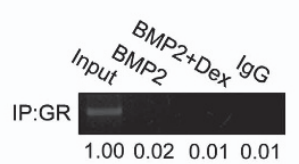

C

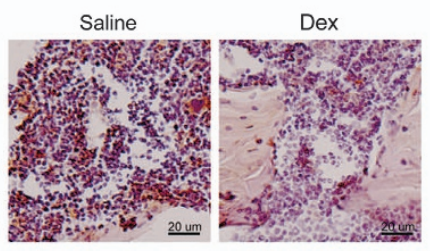

d

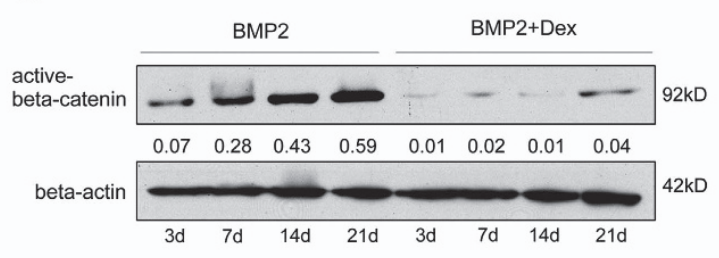

e $\square$ BMP2 $\square$ BMP2+Dex

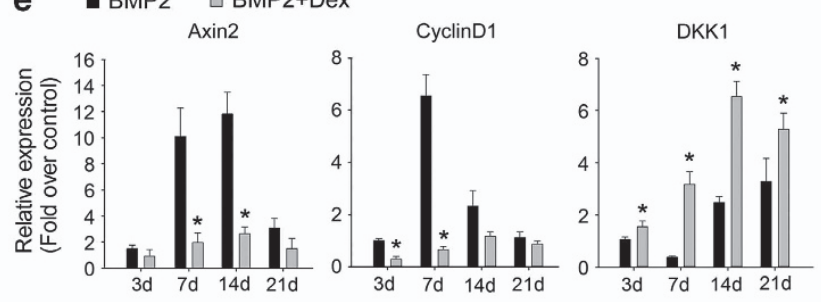

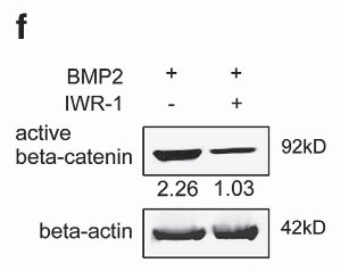

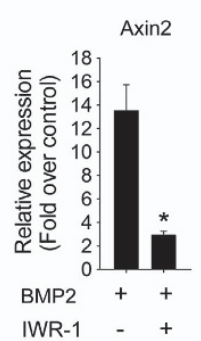

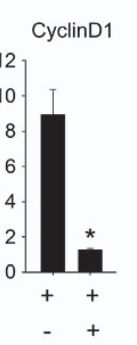

g - BMP2 $\square$ BMP2+IWR-1
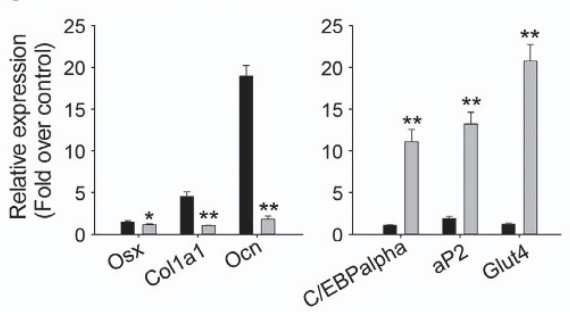
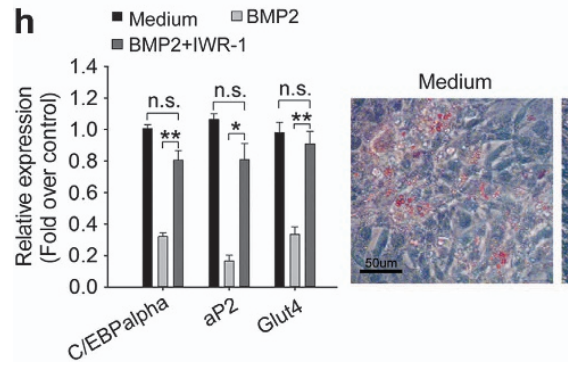

BMP2

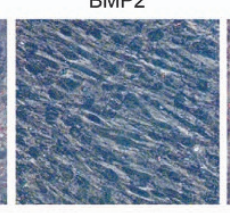

BMP2+IWR-1

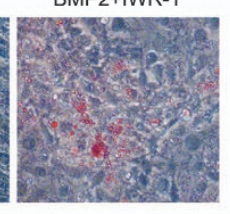

i

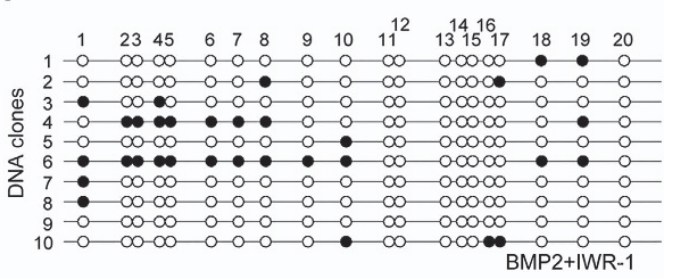

Figure 5 The Wnt/beta-catenin pathway is indispensible in BMP2-induced C/EBPalpha promoter methylation. (a) Co-IP assay shows interaction between Dnmt 3a and Dnmt 3b, but not with GR in C3H10T1/2 cells after 21 days of treatment by BMP2 and 10-6 M Dex. (b) ChIP assay shows GR did not bind to C/EBPalpha promoter in C3H10T1/2 cells after 21 days of treatment as indicated. (c) The in vivo protein level of active beta-catenin in the distal femur area of Dex- or saline-treated mice. $N=4$. (d) The protein levels of active beta-catenin in C3H10T1/2 cells treated as indicated. (e) Relative expressions of Wnt target gene Axin2 and CyclinD1, as well as Wnt inhibitor DKK1 in C3H10T1/2 cells treated as indicated. (f) C3H10T1/2 cells were treated by BMP2 with or without $10^{-6} \mathrm{M}$ IWR-1 for 7 days; the protein level of active beta-catenin and the mRNA level of Axin2 and CyclinD1 indicated the inhibition effect of IWR-1 on Wnt signaling. (g) The expression of osteoblast genes and adipocyte genes in C3H10T1/2 cells treated as indicated for 21 days. (h) In transdifferentiation assay, C3H10T1/2 cells were induced as indicated for 21 days before being switched to IFMD treatment. Adipocyte gene expression levels as well as transdifferentiated adipocytes were shown by qRT-PCR and oil red O staining, respectively. (i) DNA methylation status of C/EBPalpha promoter in C3H10T1/2 cells treated as indicated for 21 days (10 clones; Open circle: unmethylated CpG; full circle: methylated CpG, $N=3$ ). All mRNA expressions were normalized to beta-actin. Data are presented as mean \pm S.D. of three independent experiments. ${ }^{\star} P<0.05,{ }^{\star \star} P<0.01, n . s$. $P>0.05, N=3$. Densitometric analysis was shown as fold changes relative to beta-actin (western blot) or input (ChIP and Co-IP)

Adipocyte and osteoblast arise from a common precursor cell. Their fates are intertwined and share various genetic, hormonal, and environmental factors, which gives rise to questions such as what ultimately determines bone marrow stem cell fate, ${ }^{21}$ a situation that can be changed by Dex in our osteoporotic model. The specification of cell lineage is believed to be established based on genome-wide epigenetic modifications before a cell enters a differentiation program. ${ }^{22,23}$ These modifications on master regulators that guide specific lineage establishment are important.
Our previous research has concluded that expression silencing of adipocyte master regulator C/EBPalpha by DNA hypermethylation is one of the prerequisite determinants of osteoblastic fate of BMSCs and that adipocyte conversion is blocked even under IFMD once the hypermethylation state is established on the C/EBPalpha promoter. In the present study, we found that mRNA and protein levels of C/EBPalpha are highly induced by Dex both in vivo and in vitro due to the inhibited DNA methylation of its promoter. Although the protein level of Dnmt $3 a / 3 b$ did not change, the binding of both DNA methyltransferases to 
BMSCs

a
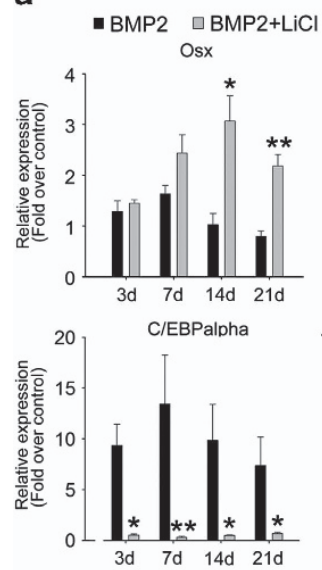
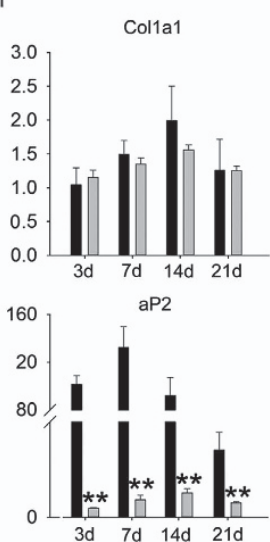
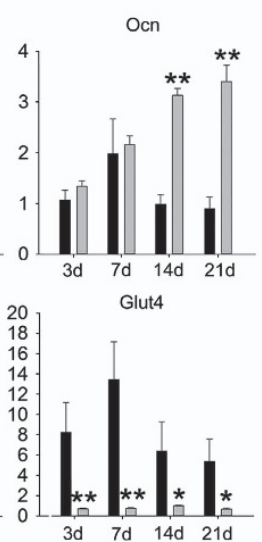

b : $\quad B M P 2$
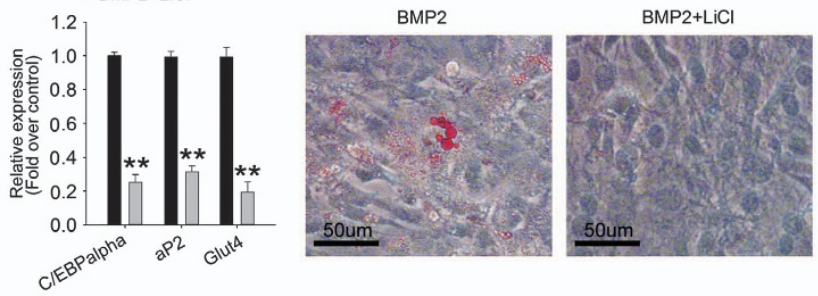

C

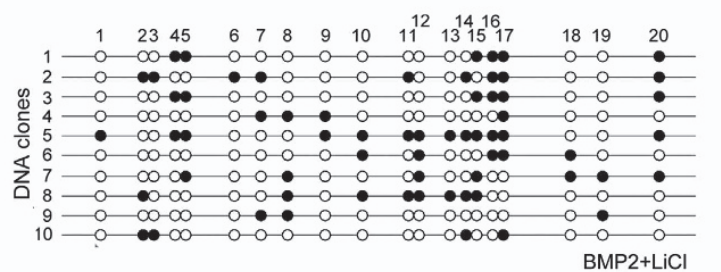

C3H10T1/2

d $\mathrm{BMP} 2+$ Dex $\square \mathrm{BMP} 2+\mathrm{Dex}+\mathrm{LiCl}$
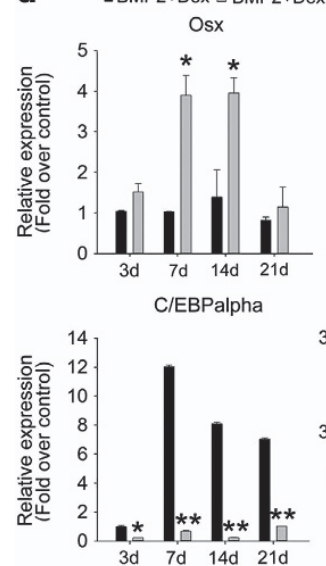
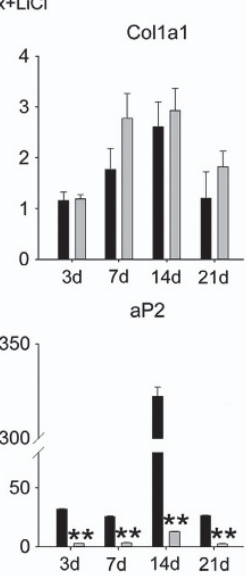

g

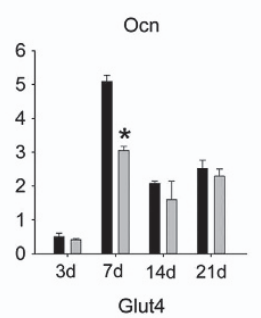

e $\quad \mathrm{BMP} 2+\mathrm{Dex}$

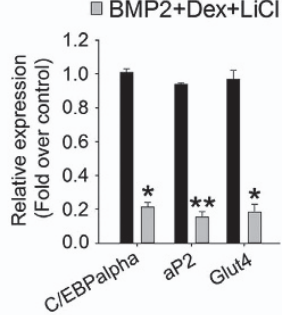

BMP2+Dex

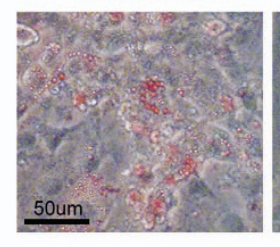

$\mathrm{BMP} 2+\mathrm{Dex}+\mathrm{LiCl}$

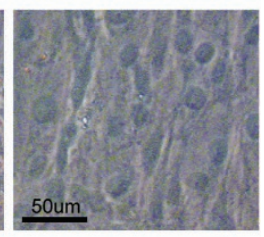

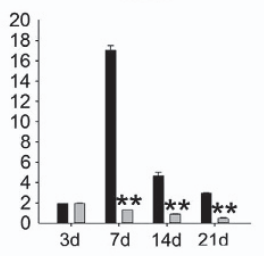

f

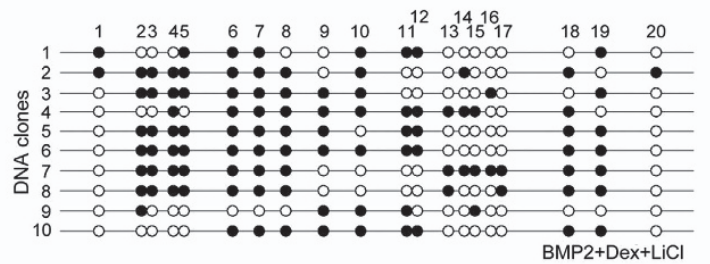

h

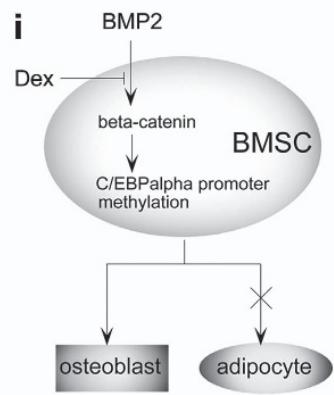

Figure $6 \mathrm{LiCl}$ rescued the effects of Dex on osteoblast differentiation and C/EBPalpha promoter methylation. (a) Relative gene expression levels in osteoporotic BMSCs treated as indicated. (b) In transdifferentiation assay, the adipocyte gene expression levels and transdifferentiated adipocytes of osteoporotic BMSCs were shown by $\mathrm{gRT}$-PCR and oil red O staining, respectively. (c) DNA methylation status of C/EBPalpha promoter in osteoporotic BMSCs treated with $100 \mathrm{ng} / \mathrm{ml}$ BMP2 plus $20 \mathrm{mM} \mathrm{LiCl}$ for 21 days (10 clones; open circle: unmethylated CpG; full circle: methylated $\mathrm{CpG}, N=3$ ). (d) Relative gene expression levels in C3H10T1/2 cells treated as indicated. (e) Relative adipocyte gene expressions as well as adipocytes in transdifferentiated C3H10T1/2 cells were shown by qRT-PCR and oil red $\mathrm{O}$ staining, respectively. (f) DNA methylation status of C/EBPalpha promoter in C3H10T1/2 cells treated as indicated for 21 days ( 10 clones; open circle: unmethylated CpG; full circle: methylated $\mathrm{CpG}, \mathrm{N}=3$ ). (g) Protein level of Dnmt 3a/3b in C3H10T1/2 cells treated as indicated for 21 days (above). $N=3$. (h) ChIP assay shows the binding of Dnmt $3 a / 3 b$ to $\mathrm{C} / \mathrm{EBPalpha}$ promoter in $\mathrm{C} 3 \mathrm{H} 10 \mathrm{~T} 1 / 2$ cells treated as indicated for 21 days. $N=3$. (i) A schematic diagram showing Dex blocks the signaling cascade activated by BMP2, and results in inhibition of C/EBPalpha promoter methylation and imbalanced osteoblast/adipocyte differentiation. All mRNA expression levels were normalized to beta-actin. Data are presented as mean \pm S.D. of three independent experiments. ${ }^{*} P<0.05,{ }^{* \star} P<0.01, N \geq 3$. Densitometric analysis was shown as fold changes relative to beta-actin (western blot) or input (ChIP) 
C/EBPalpha promoter was blocked by Dex. This result suggests that the activation of BMP2-induced methylation machinery during osteoblastogenesis was prevented. The highly expressed C/EBPalpha shifted the differentiation fate of BMSCs to adipocytes over osteoblasts, whereas its knockdown rescued the effect of Dex on BMSCs. These results confirm the determinant function of C/EBPalpha in BMSC fate, explain the molecular mechanisms of shifted BMSC differentiation balance by Dex, and increase the possibility that C/EBPalpha serves as a therapeutic target of Dex-induced osteoporosis.

Low-dose GCs are positive regulators of bone formation in vitro and in vivo. ${ }^{24,25} \mathrm{Up}$ to $10^{-9}-10^{-8} \mathrm{M}$ Dex is needed within a specific time window during human osteoblast differentiation, partly due to its ability to increase in alkaline phosphatase activity at the beginning of osteoblast development. ${ }^{26}$ Our transdifferentiation assay with $\mathrm{C} 3 \mathrm{H} 10 \mathrm{~T} 1 / 2$ also indicates that cells treated with high-dose Dex $\left(10^{-6}-10^{-7} \mathrm{M}\right)$ possessed higher adipogenic conversion potential, whereas low-dose Dex $\left(10^{-8}-10^{-9} \mathrm{M}\right)$ failed to stimulate this potential. The effects of high-dose Dex on BMP2-induced osteoblast gene expression and $m R N A$ and protein levels of C/EBPalpha were not significantly obvious in the relatively early stage (day 3 ) of osteoblast differentiation of $\mathrm{C} 3 \mathrm{H} 10 \mathrm{~T} 1 / 2$ cells but became increasingly significant with time. These results are consistent with other reports ${ }^{24-26}$ and indicate the time and the dose effects of Dex on osteoblast differentiation.

Studies indicate that Dex prevents osteoblast differentiation partly through inhibition of the Wnt/beta-catenin pathway by the following mechanisms: first, improving beta-catenin degradation by activating GSK3-beta; ${ }^{13}$ second, upregulating the secretion of Wnt inhibitors such as DKK $1^{12}$ and SFRP ${ }^{13,14}$, and third, inhibiting the transcription activities of TCF/LEF. ${ }^{13}$ Our study with the osteoporotic model also confirmed both in vivo and in vitro that the Wnt/beta-catenin pathway was inhibited by Dex, as indicated by the lower protein level of active beta-catenin and the mRNA levels of Wnt target genes Axin2 and CyclinD1. Canonical Wnt signaling can severely block adipocyte differentiation, ${ }^{10}$ so the upregulated adipocyte genes, including C/EBPalpha by Dex, are due to the inhibition of this pathway. We blocked this pathway in BMP2-induced osteoblastogenesis of C3H10T1/2 cells and found that C/EBPalpha methylation was also inhibited, whereas adipogenic conversion potential remained similar to those treated with Dex. These results demonstrate the important function of this pathway in BMP2-induced osteoblastic fate decision of BMSCs. Activation of the Wnt/ beta-catenin pathway by $\mathrm{LiCl}$ in both Dex-induced osteoporotic BMSCs and Dex-treated C3H10T1/2 cells rescued the effect of Dex in inhibiting C/EBPalpha promoter methylation and shifting the balance between osteoblastogenesis and adipogenesis, which suggest the idea of treating Dex-induced osteoporosis by activating the canonical Wnt pathway.

In conclusion (Figure 6i), one of the mechanisms of Dex-induced osteoporosis is that Dex breaks the balance between osteoblastogenesis and adipogenesis of BMSCs, thus increasing bone marrow adiposity and decreasing osteoblast number and bone formation. DNA hypermethylation of the C/EBPalpha promoter is one of the important determinants in BMP2-induced osteoblastic fate decision, so the effect of Dex on BMSC differentiation balance is partly through promoting C/EBPalpha expression by inhibiting the Wnt/betacatenin pathway, thereby inhibiting DNA hypermethylation of its distal promoter.

\section{Materials and Methods}

Animals. Six-week-old male C57BL/6J mice were purchased from Shanghai SLAC Laboratory Animal Co., Ltd, and housed five per cage under standard conditions ( $12 \mathrm{~h}$ light $/ 12 \mathrm{~h}$ dark cycle, $21^{\circ} \mathrm{C}$ controlled temperature). For Dex administration, 15 mice were injected intraperitoneally once daily with dexamethasone sodium phosphate injection solution $(50 \mathrm{mg} / \mathrm{kg}$ body weight) or with saline as a control for a period of 5 weeks. After the last injection, the mice were killed by cervical dislocation within $24 \mathrm{~h}$.

Sample preparation and skeletal morphology. For microCT analysis, right femurs of both Dex- and saline-treated mice were fixed with $4 \%$ paraformaldehyde and analyzed by Scanco Medical CT-40 instruments. For histochemistry and immunohistochemisty, distal femurs from both Dex- and salinetreated mice were fixed in $4 \%$ paraformaldehyde and embedded in paraffin, then cut longitudinally into $5-\mu \mathrm{m}$ thick sections and processed for hematoxylin and eosin staining (H\&E staining) or immunohistochemistry after decalcifying. Immunohistochemistry was performed using standard protocols with the following antibodies: C/EBPalpha (1:100) and active beta-catenin (1:200, both from Cell Signaling Technology, Inc., Danvers, MA, USA).

Cell culture. Bone marrow cells from tibia and femur of 10-12-week-old mice were flushed out with DMEM and cultured in growth medium (DMEM containing $20 \%$ fetal bovine serum (FBS), $1 \%$ penicillin-streptomycin (all from Hyclone, Logan, UT, USA)) at $37^{\circ}$ in the presence of $5 \% \mathrm{CO}_{2}$, following lysis of red blood cells. Non-adherent cells were removed by replacing the medium after 3 days. The attached BMSCs were used for experiments at passage 3. C3H10T1/2 was obtained from American Type Culture Collection (ATCC, Rockville, MD, USA) and cultured in growth medium composed of DMEM, 10\% FBS and 1\% penicillinstreptomycin at $37^{\circ}$ in the presence of $5 \% \mathrm{CO}_{2}$.

Proliferation, apoptosis, and differentiation assays. For proliferation assay, BMSCs were seeded at a density of 4000 cells/well in 96-well plates, and cell proliferation was monitored after indicated time points by MTT assay (3-(4, 5dimethylthiazol-2-yl)-2, 5-diphenyltetrazolium bromide, a yellow tetrazole). For apoptosis, BMSCs were plated at the density of $1 \times 104 \mathrm{cells} / \mathrm{cm}^{2}$ and cultured overnight. TUNEL staining was performed using Cell Death Detection kit (Roche, Mannheim, Germany) according to manufacturer's instructions. Statistic analysis was performed by cell counting. For osteoblast differentiation assay, BMSCs or C3H10T1/2 cells were plated at the density of $1 \times 10^{4} \mathrm{cells} / \mathrm{cm}^{2}$ and induced by $100 \mathrm{ng} / \mathrm{ml}$ hBMP2 (R\&D System) in growth medium for the indicated time points. For transdifferentiation assay, cells were cultured with indicated inducers for 21 daysays before switching to adipogenic hormonal cocktail composed of $10 \mu \mathrm{g} / \mathrm{ml}$ insulin, $10 \%$ FBS, $0.5 \mathrm{mM}$ methylisobutylxanthine and $10^{-6} \mathrm{M}$ Dex (IFMD), and cultured for another 8 days. Inducers were purchased from Sigma-Aldrich (Dex, methylisobutylxanthine, insulin, LiCl, IWR-1, and 5-azacytidine) or R\&D System (hBMP2).

RNA purification and quantitative real-Time PCR (qRT-PCR). Total RNA was prepared using TRIzol reagent (Invitrogen, Mulgrave, Australia) according to the manufacturer's instructions. First-strand CDNA was synthesized from $1 \mu \mathrm{g}$ of total RNA by incubating for $1 \mathrm{~h}$ at $42^{\circ}$ with Superscript III reverse transcriptase (Invitrogen) following oligo(dT) priming. After reverse transcription reaction, qRT-PCR was performed by LightCycler480 system (Roche) using SYBR1Premix Ex TaqTM (Takara, Dalian, China) according to the manufacturer's instructions. All amplifications were normalized by beta-actin. Data were analyzed using the comparison $\mathrm{Ct}\left(2^{-\Delta \Delta C t}\right)$ method $^{27}$, and expressed as fold change compared with respective control. Each sample was analyzed in triplicate. The primer sequences used in this study were as follows, Osx: forward, $5^{\prime}-\mathrm{CCC}$ TTCTCAAGCACCAATGG-3'; reverse, 5'-AAGGGTGGGTAGTCATTTGCATA-3'; Col1a1: forward, 5'-GAAGTCAGCTGCATACAC-3'; reverse: 5'-AGGAAGTCC AGGCTGTCC-3'; Ocn: forward, 5'-AGGGCAATAAGGTAGTGAA-3'; reverse, 5'-GAGGCTCTGAGAAGCATAAA-3'; C/EBPalpha: forward, 5'-GTTAGCCATGTG GTAGGAGACA-3'; reverse, 5'-CCCAGCCGTTAGTGAAGAGT-3'; aP2: forward, 5'-AAATCACCGCAGACGACA-3'; reverse, 5'-CACATTCCACCACCAGCT-3'; 
Glut4: forward, 5'-CTTGGCTCCCTTCAGTTTG-3'; reverse, 5'-TGCCTTGTGG GATGGAAT-3'; Axin2: forward, 5'-TGACTCTCCTTCCAGATCCCA-3'; reverse, 5'-TGCCCACACTAGGCTGACA-3'; CyclinD1: forward, 5'-GCGTACCCTGACAC CAATCTC-3'; reverse, 5'-CTCCTCTTCGCACTTCTGCTC-3'; DKK1: forward, $5^{\prime}$-CTCATCAATTCCAACGCGATCA-3'; reverse, 5'-GCCCTCATAGAGAACTCCC G-3'; beta-actin: forward, $5^{\prime}$-CCCTGTATGCCTCTGGTC-3'; reverse, $5^{\prime}$-GTCTT TACGGATGTCAACG-3'.

Oil red $\mathrm{O}$ staining. Cells were washed three times with phosphate-buffered saline (PBS) and then fixed for 2 min with $3.7 \%$ formaldehyde in PBS. Oil Red 0 $(0.5 \%)$ in isopropanol was diluted with $2 / 3$ volumes of water, filtered and added to the fixed cell monolayers for $1 \mathrm{~h}$ at room temperature. The cell monolayers were then washed with $70 \%$ ethanol, and the stained triglyceride droplets in the cells were visualized under microscope.

Western blotting. Cells were lysed on ice for $30 \mathrm{~min}$ in lysis buffer containing $50 \mathrm{mM}$ Tris- $\mathrm{HCl}, \mathrm{pH} 7.4,150 \mathrm{mM} \mathrm{NaCl}, 1 \%$ Nonidet P-40, and $0.1 \%$ SDS supplemented with protease inhibitors $(10 \mathrm{mg} / \mathrm{ml}$ leupeptin, $10 \mathrm{mg} / \mathrm{ml}$ pepstatin $\mathrm{A}$, and $10 \mathrm{mg} / \mathrm{ml}$ aprotinin). For western analysis, $50 \mu \mathrm{g}$ of protein sample was resolved on 10\% SDS-PAGE and electrotransferred onto nitrocellulose membranes (Whatman, Piscataway, NJ, USA). The primary antibodies used were anti-C/EBPalpha (1:1000), anti-active-beta-catenin (1:1000); anti-Dnmt 3a (1:200) and Dnmt 3b (1:125, both from Abcam, Cambridge, MA, USA). Beta-actin was used as loading control. HRP-conjugated secondary antibodies were used at a 1:5000 dilution. The antigen-antibody complexes were visualized using the enhanced chemiluminescence detection system (Millipore, Billerica, MA, USA), as recommended by the manufacturer. Immunoreactive bands were quantitatively analyzed in triplicate by normalizing the band intensities to beta-actin on scanned films with Alpha Image software.

Co-immunoprecipitation (Co-IP). The cells were solubilized in cOmplete lysis-M (Roche) with protease inhibitor cocktail (Upstate), and the lysates were clarified by centrifugation. For input screening, a small aliquot from each sample was separated at this stage. After pre-clearing with Protein A/G agarose beads (Upstate), the cell lysates were incubated with anti-GR (Abcam), anti-Dnmt 3a/3b antibody overnight at $4^{\circ}$ with gentle shaking. Unspecific IgG was used as a control. The immunocomplexes were captured by incubating with Protein $A / G$ agarose bead slurry for $2 \mathrm{~h}$ at $4^{\circ}$ with gentle shaking. After washing, the beads were resuspended in $2 \times$ SDS loading buffer and boiled. SDS-PAGE and immunoblots were performed as described above with anti-GR and anti-Dnmt 3a/3b antibodies.

Bisulfite sequencing. Cells were lysed for $10 \mathrm{~min}$ in lysis buffer $(10 \mathrm{mM}$ Tris- $\mathrm{HCl}, \mathrm{pH} 8,100 \mathrm{mM}$ EDTA, $0.5 \%$ SDS) and digested with $0.1 \mathrm{mg} / \mathrm{ml}$ Proteinase $\mathrm{K}$ overnight. Bisulfite conversion was perfomed as previously described $^{11}$, with modifications. Briefly, $1 \mu \mathrm{g}$ Genomic DNA was treated with $2.4 \mathrm{M}$ sodium bisulfite and $123 \mathrm{mM}$ hydroquinone (both from Sigma-Aldrich). Reactions were desalted using a QIAEX II gel extraction kit (Qiagen). The converted DNA samples were amplified with primers as follows for the $\mathrm{CpG}$ island region of C/EBPalpha: forward, 5'-TGGGTGTTTATTAGGTTTTTTTTGT-3'; reverse, 5'-ATTCATAAAAACACTAATCTCTATAACTC-3'. Successful PCR products were then cloned into pMD19-T vector (TaKaRa, China). Ten random clones were isolated from a PCR amplicon and sequenced.

ChIP assay. ChIP assay were performed using EZ ChIP Chromatin Immunoprecipitation Kit (Millipore, Upstate) according to the manufacturer's instructions. Briefly, cells cultured under the indicated conditions were fixed in 1\% formaldehyde/PBS for $10 \mathrm{~min}$ at room temperature. After two washes with PBS, cells were resuspended in $0.5 \mathrm{ml}$ of lysis buffer containing a protease inhibitor cocktail before sonication. DNA fragments from soluble chromatin preparations were 400-800 bp in length. Immunoprecipitation (IP) was carried out overnight with GR, Dnmt 3a and Dnmt3b antibodies or normal mouse IgG as a negative control. Protein $A / G$ agarose was used to pulldown the antigen-antibody compounds and then washed four times with washing buffers. The DNA-protein crosslinks were reversed with $5 \mathrm{M} \mathrm{NaCl}$ at $65^{\circ}$ for $6 \mathrm{~h}$, and DNA from each sample was purified. PCR was performed with $2 \mu$ l DNA samples with the following primers: foward, 5'-GAGACGTGGGTGCTCACC-3'; reverse, 5'-TTCTTTCCCTAC TGTCATTCA $-3^{\prime}$. The PCR products were analyzed by $2 \%$ agarose gel electrophoresis.
Construction of lentiviral shRNA stable transfectants of osteoporotic cells. The lentiviral vector $\mathrm{pGPH} 1 / \mathrm{NeO}+\mathrm{GFP}$ that contain either C/EBPalpha-specific shRNA (shC/EBPalpha, 5'-TTCTCCGAACGTGTCA CGTTTC-3') or control sequence (shcontrol) were constructed by Genepharma Company (Shanghai, China). Lentiviral particles were prepared as described else where. Stable shRNA transfectants were selected by puromycin (Sigma-Aldrich) $72 \mathrm{~h}$ after lentivirus infection. The stable transfected cells were used for further studies.

Statistical analysis. Statistically significant differences were determined using Student's $t$-test or two-way analysis of variance. A $P$-value $<0.05$ was considered significant. All values are presented as the mean \pm S.D.

\section{Conflict of Interest}

The authors declare no conflict of interest.

Acknowledgements. This work was supported by grants from The Ministry of Science and Technology of China (No. 2011DFA30790, 2010CB945600), National Natural Science Foundation of China (No. 81190133, 31101056), Chinese Academy of Sciences (No. XDA01030404, KSCX2-EW-Q-1-07), Science and Technology Commission of Shanghai Municipality (No. 12411951100, 12410708600, 13430710700), Shanghai Municipal Education Commission (No. J50206).

\section{Author Contributions}

Jiao Li: conception and design, manuscript writing, collection of data, data analysis and interpretation; Ning Zhang: collection of data, data analysis and interpretation; Xiaoju Huang: provision of study material; Jiake Xu and Julio C Fernandes: data analysis and manuscript revision; Xiaoling Zhang and Kerong Dai: conception and design, manuscript revision, final approval of manuscript.

1. Weinstein RS. Glucocorticoid-induced osteoporosis and osteonecrosis. Endocrinol Metab Clin North Am 2012; 41: 595-611.

2. van Staa TP, Leufkens HG, Cooper C. The epidemiology of corticosteroid-induced osteoporosis: a meta-analysis. Osteoporos Int 2002; 13: 777-787.

3. Yao W, Cheng Z, Busse C, Pham A, Nakamura MC, Lane NE. Glucocorticoid excess in mice results in early activation of osteoclastogenesis and adipogenesis and prolonged suppression of osteogenesis: a longitudinal study of gene expression in bone tissue from glucocorticoid-treated mice. Arthritis Rheum 2008; 58: 1674-1686

4. Muruqanandan S, Roman AA, Sinal CJ. Adipocyte differentiation of bone marrow-derived mesenchymal stem cells: cross talk with the osteoblastogenic program. Cell Mol Life Sci 2009; 66: 236-253.

5. Abdallah BM, Kassem M. New factors controlling the balance between osteoblastogenesis and adipogenesis. Bone 2012; 50: 540-545.

6. Ducy P, Zhang R, Geoffroy V, Ridall AL, Karsenty G. Osf2/Cbfa1: a transcriptional activator of osteoblast differentiation. Cell 1997; 89: 747-754.

7. Nakashima K, Zhou X, Kunkel G, Zhang Z, Deng JM, Behringer RR et al. The novel zinc finger-containing transcription factor osterix is required for osteoblast differentiation and bone formation. Cell 2002; 108: 17-29.

8. Rosen ED, Walkey CJ, Puiqserver P, Spieqelman BM. Transcriptional regulation of adipogenesis. Genes Dev 2000; 14: 1293-1307.

9. Jeon MJ, Kim JA, Kwon SH, Kim SW, Park KS, Kim SY et al. Activation of peroxisome proliferator-activated receptor-gamma inhibits the Runx2-mediated transcription of osteocalcin in osteoblasts. J Biol Chem 2003; 278: 23270-23277.

10. Kanq S, Bennett CN, Gerin I, Rapp LA, Hankenson KD, Macdougald OA. Wnt signaling stimulates osteoblastogenesis of mesenchymal precursors by suppressing CCAAT/ enhancer-binding protein alpha and peroxisome proliferator-activated receptor gamma. $J$ Biol Chem 2007; 282: 14515-14524.

11. Fan $Q$, Tang $T$, Zhang $X$, Dai $K$. The role of CCAAT/enhancer binding protein (C/EBP)alpha in osteogenesis of C3H10T1/2 cells induced by BMP-2. J Cell Mol Med 2009; 13 : 2489-2505.

12. Wang FS, Ko JY, Dw Yeh, Ke Hc WuHL. Modulation of Dickkopf-1 attenuates glucocorticoid induction of osteoblast apoptosis, adipocytic differentiation, and bone mass loss. Endocrinology 2008; 149: 1793-1801.

13. Smith E, Frenkel B. Glucocorticoids inhibit the transcriptional activity of LEF/TCF in differentiating osteoblasts in a glycogen synthase kinase-3beta-dependent and -independent manner. J Biol Chem 2005; 280: 2388-2394.

14. Wang FS, Lin CL, Chen YJ, Wang CJ, Yang KD, Huang YT et al. Secreted frizzled-related protein 1 modulates glucocorticoid attenuation of osteogenic activities and bone mass. Endocrinology 2005; 146: 2415-2423.

15. Milat $\mathrm{F}, \mathrm{Ng} \mathrm{KW}$. Is Wnt signalling the final common pathway leading to bone formation? Mol Cell Endocrinol 2009; 310: 52-62. 
16. Jho EH, Zhang T, Domon C, Joo CK, Freund JN, Costantini F. Wnt/beta-catenin/Tct signaling induces the transcription of Axin2, a negative regulator of the signaling pathway. Mol Cell Biol 2002; 22: 1172-1183.

17. Tetsu O, McCormick F. Beta-catenin regulates expression of cyclin D1 in colon carcinoma cells. Nature 1999; 398: 422-426.

18. Chen B, Dodge ME, Tang W, Lu J, Ma Z, Fan CW et al. Small molecule- mediated disruption of Wnt-dependent signaling in tissue regeneration and cancer. Nat Chem Biol 2009; 5: 100-107.

19. Rodriguez JP, Montecinos L, Rios S, Reyes P, Martinez J. Mesenchymal stem cells from osteoporotic patients produce a type I collagen-deficient extracellular matrix favoring adipogenic differentiation. J Cell Biochem 2000; 79: 557-565.

20. Rodriguez JP, Astudillo P, Rios S, lino AM. Involvement of adipogenic potential of human bone marrow stromal cells (MSCs) in osteoporosis. Curr Stem Cell Res Ther 2008; 3 : 208-218.

21. Rosen CJ, Bouxsein ML. Mechanisms of disease: is osteoporosis the obesity of bone? Nat Clin Pract Rheumatol 2006; 2: 35-43.

22. Reik W. Stability and flexibility of epigenetic gene regulation in mammalian development. Nature 2007; 447: 425-432

23. Thomas D, Kansara M. Epigenetic modifications in osteogenic differentiation and trans formation. J Cell Biochem 2006; 98: 757-769.
24. Azuma K, Urano T, Ouchi $Y$, Inoue S. Glucocorticoid-induced gene tripartite motifcontaining 63 (TRIM63) promotes differentiation of osteoblastic cells. Endocr J 2010; 57: 455-462.

25. Kalak R, Zhou H, Street J, Day RE, Modzelewski JR, Spies CM et al. Endogenous glucocorticoid signalling in osteoblasts is necessary to maintain normal bone structure in mice. Bone 2009; 45: 61-67.

26. Eijken M, Koedam M, van Driel M, Buurman CJ, Pols HA, van Leeuwen JP. The essential role of glucocorticoids for proper human osteoblast differentiation and matrix mineralization. Mol Cell Endocrinol 2006; 248: 87-93.

27. Pfaffl MW. A new mathematical model for relative quantification in real-time RT-PCR. Nucleic Acids Res 2001; 29: e45.

Cell Death and Disease is an open-access journal published by Nature Publishing Group. This work is licensed under a Creative Commons Attribution-NonCommercialShareAlike 3.0 Unported License. To view a copy of this license, visit http://creativecommons.org/licenses/by-nc-sa/3.0/ 